\title{
Poverty Reduction Effect of New-Type Agricultural Cooperatives: An Empirical Analysis Using Propensity Score Matching and Endogenous Switching Regression Models
}

\author{
Zhineng Hu, Qiong Feng $\mathbb{D}^{\mathbb{D}}$, Jing Ma, and Shuangyi Zheng $\mathbb{D}$ \\ Business School, Sichuan University, Chengdu, Sichuan Province 610064, China \\ Correspondence should be addressed to Shuangyi Zheng; syzheng@scu.edu.cn
}

Received 31 March 2021; Revised 16 May 2021; Accepted 25 May 2021; Published 10 June 2021

Academic Editor: Guoqiang Wang

Copyright ( 2021 Zhineng Hu et al. This is an open access article distributed under the Creative Commons Attribution License, which permits unrestricted use, distribution, and reproduction in any medium, provided the original work is properly cited.

\begin{abstract}
Agricultural cooperatives have been found to effectively alleviate poverty in developing countries because of their specific socioeconomic functions that allow poor households to overcome marketing and production constraints. However, cooperative evaluations are inevitably influenced by other poverty alleviation measures and rarely consider the characteristics of specific ethnic groups. Using cross-sectional surveys in Southwest China and employing propensity score matching (PSM) and endogenous switching regression (ESR) models, this paper analyzed the participation of poor households in New-type Agricultural Cooperatives (NACs) in ethnic areas and assessed the income impacts of NAC membership by eliminating unobserved biases and group heterogeneity. This study detected heterogeneous policy perceptions and behavioral differences between the member and nonmember groups, and the PSM and ESR model results indicated that, overall, participation in the NACs had a positive effect on household income. The ESR model was found to be more plausible as it was able to reveal the significant income gaps under a counterfactual inference framework. Local policymakers need to focus on the policy perception and behavioral and earning capability differences between groups and increase the balanced policy implementation.
\end{abstract}

\section{Introduction}

Poverty alleviation to narrow rural-urban gaps and eliminate poverty is a global challenge $[1,2]$. China has made outstanding contributions to global poverty alleviation since implementing its targeted poverty alleviation (TPA) strategy in 2013 [3]. Industrialized poverty alleviation (IPA) has been found to be an effective method for promoting sustainable development in poverty-stricken areas and households in developing countries [4].

However, poor smallholders usually face constraints such as high transaction costs of accessing output markets, lack of modern agricultural technologies, and poor access to production services and credit services that hinder poor households participating in IPA and economically empower the rural poor [5-10].

In China, as in other developing countries such as Ethiopia, Kenya, and Rwanda, agricultural cooperatives are third sector organizations designed to overcome the constraints hindering poor households participating in IPA, economically empower the rural poor, and boost rural development [11-13].

Many measures have been developed to enhance the development capacity of poor households and alleviate poverty [14]. However, as any success associated with agricultural cooperatives is entangled with other poverty alleviation measures, it has been difficult to accurately identify the impacts. Further, the decision whether or not to participate in a cooperative is based on households selfselection; thus, both observable factors (e.g., age, education, education, and household size) and unobservable factors (e.g., the disparities between minorities and nonminorities and the perceptive differences between ethnic groups) that influence farmers decisions may result in sample selection bias $[9,15,16]$. If not taking possible selection biases into account, the deep-seated intragroup inequities and policy implementation deviations may still exist [17-19]. 
To estimate the causal treatment effects of cooperative membership, most of the studies have employed propensity score matching (PSM) model to account for selection bias $[5,20-22]$. However, a well-known shortcoming of the PSM model is that it accounts for selection bias only by controlling observable actors, without controlling unobservable factors, which may result in biased estimates. Ma and Abdulai [23] used an endogenous switching regression (ESR) to analyze both the determinants of cooperative membership and the impact of membership on household income separately for members and nonmembers.

Therefore, taking China's New-type Agricultural Cooperatives (NACs) as examples, this study sought to identify the interference factors preventing household participation in rural cooperatives and detect how and to what extent these cooperatives have affected the incomes of poor rural households. By controlling the selection biases, propensity score matching (PSM) was used to estimate the different causal treatment effects between the cooperative members and similar nonmembers, and an endogenous switching regression (ESR) was used to implement the PSM under further counterfactual inference to eliminate any heterogeneity.

The remainder of this paper is structured as follows. Section 2 briefly reviews the determinants and impacts of cooperative membership. Section 3 presents the methodology: the sampling procedure, data collection, considered variables, and analytical procedures: Section 4 details the empirical results and discusses the findings, and Section 5 gives the conclusion and the implication.

\section{Literature Review}

2.1. Cooperative Membership Determinants. The main influencing factors for agricultural cooperative participation have revealed implicit preference perspectives and similar studies on farmer participation [24, 25] determinants have revealed demographic, socioeconomic, and physical influence factors, such as age, education level, marital status, health status, family size, labor size, and land size.

Implicit influencing factors have been elucidated by observing household societal and psychological conditions [26-28] and examining farmer social network conditions, such as the number of clients, production price knowledge, social capital maintenance, information acquisition, infrastructure, service support, and rural credit [29, 30]. For example, Wossen et al. [10] concluded that the more reliable the psychological security, the more willing the households to participate in cooperatives to obtain greater economic benefits. Governments have also been found to have a significant positive impact on household willingness to participate in agricultural cooperatives [31, 32].

In ethnically diverse poor households, the various policy contradictions and cooperative membership structures are highly heterogeneous, which means that heterogeneous policy perceptions are possibly an important factor [33]. This paper modeled NAC membership based on socioeconomic characteristics and the policy perception characteristics of the households, with the particular proxy policy perception variables being space distance (distance to the village main road), group distance (being a minority or not), and psychological distance (benefited from other policies or not).

\subsection{Role of Cooperatives in Rural Development and Poverty} Alleviation. Cooperatives can stimulate rural industrialization, improve household productivity [34, 35], and enhance market power by harnessing the benefits of the economies of scale gained from collective commercialization or the through the creation of new vertical marketing links [36-38]. It has been found that, compared to competitors, agricultural cooperatives offer better or more stable prices for a variety of products to their members $[39,40]$ and also function as market extenders for both members and nonmembers by increasing the product prices for buyers within the areas they operate [41].

A growing number of studies have investigated the impacts of cooperative membership for farmers. Agricultural cooperatives can significantly contribute to members' technology adoption in developing countries [10, 17, 42, 43], enhance market power by harnessing the benefits of the economies of scale gained from collective commercialization or the through the creation of new vertical marketing links $[6,44-47]$, improve crop yields and farm revenue $[5,23,48,49]$, elevate farm efficiency and financial performance $[15,50-52]$, and promote farmers' safe production $[53,54]$.

However, in some cases, it has been found that cooperatives do not have any advantages for some provided services, such as access to knowledge and new technologies $[55,56]$, and contrary to the expected goal of redistribution, some practice social exclusion $[57,58]$. As cooperatives in some areas are organized and controlled by government agencies, they are specifically focused on the specific political and economic interests of private companies and local elites and therefore do not benefit the poorer households [59], who also often lack access to formal service channels because of their low incomes and the perceived risk of default [4].

To understand the impact of poverty alleviation programs over time, many case studies and statistical models, including ordinary least squares (OLS) [60], PSM [59], and quantile regression [61], and linear programming methods, including analytic hierarchy process (AHP) [62] and data envelopment analysis (DEA) [63], have been applied. Given the challenges associated with quantifying causal relationships in complex socioecological systems, a small number of observational (nonexperimental) studies have employed causal inference to detect the causal effects of poverty alleviation programs $[64,65]$.

Because of the multiple causes of poverty and the multiple sources of income growth, such as income from working outside and policy subsidies, to exclude the entangled effects (unobservable bias) and endogenous biases from counterfactual causal inference frameworks, this paper used PSM and ESR approaches to detect the impacts of the agricultural cooperatives and the possible causalities. 


\section{Methodology}

3.1. Sampling and Data Collection. A multistage sampling procedure was used to collect the data. First, Wuling Mountain Area, one of the 14 contiguous extremely poor areas with special difficulties in Southwest China, was purposively selected, because the development of NACs in Wuling Mountain Area is relatively good among the 14 contiguous extremely poor areas with the characteristics of multiethnic, integrated cultures.

Second, in order to better select the sampling counties and reduce the sample imbalance, the clustering method was used to cluster 37 national key poverty-stricken counties in Wuling Mountain area. According to the poverty incidence of each county in 2014, the poverty status of the sampling counties in the base period (2014) was distinguished. The results show that $F=97.579$, Sig $<0.001$, and the overall clustering effect is better; 37 counties were clustered into four types of poverty, and the characteristics of different poverty counties (cities and districts) are different. Based on the results, seven sampling countries were confirmed with local poverty alleviation and development workers on the cooperative development situations from 2014 to 2018. Third, thirty villages that had village-level NACs in 2014 were randomly selected.

Finally, approximately 20-30 households in each village were randomly selected using the village-level poor households' information provided by the village committee. The data used in the analysis were from a cross-sectional household survey of the 853 poor households in 2018 .

The NAC membership status was considered; therefore, 853 poor households were finally randomly selected: 238 NAC member households and 615 nonmember households. As NAC participation was voluntary, local governments do not force households to join, and the cooperatives' behaviors were regulated by the national law on Farmers Professional Cooperatives.

3.2. Analytical Frameworks and Estimation Strategies. PSM and ESR, which are both two-stage frameworks, were used to, respectively, model the household decisions to join the cooperatives and the impact of cooperative membership on household incomes.

3.2.1. Variable Selection. The NAC membership income impact was expressed as

$$
\begin{aligned}
& Y_{i}=\alpha C_{i}+\beta X_{i}+u_{i}, \\
& C_{i}^{*}=Z_{i} \gamma+v_{i} \text { with } C_{i}= \begin{cases}1, & \text { if } C_{i}^{*}>0, \\
0, & \text { otherwise }\end{cases}
\end{aligned}
$$

where $Y_{i}$ is the income per capita in household $i ; C_{i}$ is a dummy variable as to whether the household $i$ is an NAC member, 1 if household $i$ is in an NAC and 0 otherwise; $X_{i}$ is a group of other variables that affected household income; $Z_{i}$ is a function of the observed covariates that affected household decision-making in the latent variable model; $u_{i}$ is the residual subjected to independent and identical distribution (IID); $v_{i}$ is the error term with a zero mean; and $\alpha$ is a vector of unknown parameters.

Four variable types were considered in the propensity score model: those that measured the baseline covariates; those associated with treatment assignment; those that affected the outcome (the potential confounders); and those that affected both the treatment assignment and the outcomes (the true confounders). The models that included only the potential confounders or only the true confounders formed the greater number of matched pairs and resulted in a lower mean squared error for the null treatment effect estimates than the other two propensity score models. All variables included in the models were measured before participation and were not affected by the treatment.

This study used three groups of variables: (1) outcome per capita household income in 2018, (2) NAC membership treatment, and (3) observable pretreatment covariates that included the confounders: socioeconomic household characteristics and policy perception proxies.

Household income was taken as the 2018 per capita income in Chinese yuan (CNY) (labeled as In 2018), the NAC membership categorical variable was 1 if the household was an NAC member and 0 otherwise, the socioeconomic household characteristics were family size (labeled as Fsize), highest education level (labeled as Education), migrant worker size (labeled as Mwsize), health status (labeled as Health), and household land size (labeled as Landsize), and the policy perception characteristics were distance to the village main road (labeled as Distance), nationality (labeled as Nationality), and enjoyment of other policies (labeled as Policy). The highest education level, health status, minority, and enjoyment of other policies were all taken as the categorical variables (Table 1 ).

A $t$-test was used for the continuous variables and Pearson's $\chi^{2}$ statistic was used for the categorical variables to compare the characteristics between the two groups. As can be seen in the descriptive statistics in Table 1, a household was more likely to participate in an NAC if they were a minority; had a primary school or college education level; had fewer household members and fewer migrant workers and more land area; lived closer to the village main road; and accessed other policies. It was found that the NAC member incomes had increased by $738 \mathrm{CNY}$; therefore, there was a slight difference in the selected variables between the two groups (participation and nonparticipation in an NAC); however, as the confounding factors needed to be conditioned, these results were inadequate to make any inferences regarding the impact of NAC membership on member incomes. Therefore, more relatively robust analyses (using PSM and ESR) were conducted to ensure more reliable results.

\subsubsection{Propensity Score Matching. Propensity score matching} (PSM) provides an unbiased estimate of a treatment's impact under three assumptions: a conditional independence assumption (CIA) or unconfoundedness; a common support or overlap assumption; and the balancing property 
TABLE 1: Descriptive Statistics and comparison of NAC membership characteristics.

\begin{tabular}{|c|c|c|c|c|c|}
\hline \multirow{2}{*}{ Variables } & \multirow{2}{*}{ Definition } & \multirow{2}{*}{$\begin{array}{c}\text { Members }(N=238) \\
\text { No. }(\%)\end{array}$} & \multirow{2}{*}{$\begin{array}{l}\text { Nonmembers } \\
(N=615) \\
\text { No. }(\%)\end{array}$} & \multirow{2}{*}{\multicolumn{2}{|c|}{$\begin{array}{l}p \text { value } \\
\text { Pearson } \chi^{2} \\
\text { statistic }\end{array}$}} \\
\hline & & & & & \\
\hline In 2018 & Household income per capita in 2018 (CNY) & $\begin{array}{c}7837(4245,3000 \text {, and } \\
40371)\end{array}$ & $\begin{array}{l}7099(3523,0 \text {, and } \\
28106)\end{array}$ & $0.0175^{* *}$ & \\
\hline Fsize & Number of family members & $2.4(1.64,1$, and 9$)$ & $3.197(1.6,1$, and 7$)$ & $0.0060^{* * *}$ & \\
\hline Mwsize & Number of migrant workers & $1.4(1.10,0$, and 4$)$ & $1.658(1.11,0$, and 5$)$ & $0.0052^{* * *}$ & \\
\hline Landsize & Log land area per capita & $7.2(1.58,0$, and 9.5$)$ & $6.752(1.9,0$, and 9.9$)$ & $0.0004^{* * *}$ & \\
\hline Distance & Distance to the village main road $(\mathrm{km})$ & $0.59(0.95,0$, and 7$)$ & $0.76(1.2,0$, and 12$)$ & $0.0270^{* *}$ & \\
\hline Nationality & & & & & $\leqslant 0.001^{* * *}$ \\
\hline Miao & Miao nationality ( $1=$ yes; 0 otherwise $)$ & $74(31.1)$ & $231(37.6)$ & & \\
\hline Tujia & Tujia nationality ( $1=$ yes; 0 otherwise $)$ & $125(52.5)$ & $154(25)$ & & \\
\hline Han & Han nationality (reference) & $39(16.4)$ & $230(37.4)$ & & \\
\hline Education & Highest household education level & & & & $0.0021^{* * *}$ \\
\hline College & $\begin{array}{c}\text { Greater than or equal to college }(1=\text { yes; } 0 \\
\text { otherwise })\end{array}$ & $36(15.1)$ & $65(10.56)$ & & \\
\hline High & $\begin{array}{c}\text { Senior high school/technical }(1=\text { yes; } 0 \\
\text { otherwise })\end{array}$ & $19(8)$ & $80(13)$ & & \\
\hline Middle & Journal high school $(1=$ yes; 0 otherwise $)$ & $102(42.9)$ & $321(52.2)$ & & \\
\hline Primary & Primary $(1=$ yes; 0 otherwise $)$ & $77(32.3)$ & $137(22.28)$ & & \\
\hline Illiterate & $\begin{array}{l}\text { Household members are all not educated } \\
\text { (reference) }\end{array}$ & $4(1.7)$ & $12(1.96)$ & & \\
\hline Health & & & & & 0.7699 \\
\hline Healthy & $\begin{array}{c}\text { Household members are healthy }(1=\text { yes; } 0 \\
\text { otherwise })\end{array}$ & $122(51.3)$ & $309(50.244)$ & & \\
\hline Sick & $\begin{array}{l}\text { Household members are sick but able to work } \\
\qquad(1=\text { yes; } 0 \text { otherwise })\end{array}$ & $104(43.7)$ & $267(43.415)$ & & \\
\hline Disability & Household members are disabled (reference) & $12(50)$ & $39(6.341)$ & & \\
\hline Policy & & & & & $0.0012^{* * *}$ \\
\hline Policy & $\begin{array}{c}\text { Enjoyed other policies before } 2014(1=\text { yes; } 0 \\
\text { otherwise })\end{array}$ & $132(55.5)$ & $265(43.1)$ & & \\
\hline No-policy & $\begin{array}{c}\text { Not enjoyed other policies before } 2014 \\
\text { (reference) }\end{array}$ & $106(44.5)$ & $350(56.9)$ & & \\
\hline
\end{tabular}

Note. Significance level: ${ }^{*} 10 \%,{ }^{* *} 5 \%$, and ${ }^{* * *} 1 \%$ for the $t$-test and $\chi^{2}$ test, respectively. Continuous data are presented as mean (standard deviations, minimum, and maximum), and categorical data are presented as frequencies with percentages.

fulfillment assumption. As stated, the variables chosen in this paper were based on China's TPA criteria and therefore were well matched to the actual area and group situations and basically satisfied the CIA assumption that there were few missing explanatory variables and the missing variable deviation was small.

First, the log-likelihood function was employed to select the matching covariates. Generally, model fit or parsimony is not a concern when estimating a propensity score model as the goal is to find a model that results in the best covariate balance. Second, logit regression was used to estimate the propensity score, with the PSM being implemented using four matching algorithms, the fournearest neighbor, kernel, radius matching, and nearest neighbor within caliper, to compare the outcomes from the treated group with the comparison and check the results robustness. Finally, after ensuring the fulfillment of the common support and balancing property assumptions, the average treatment effect (ATT) was calculated [66], that is, the average effect on household income of those households participating in an NAC:

$$
\operatorname{ATT}=E\left(Y_{1 i}-Y_{0 i} \mid C=1\right)=\frac{1}{N_{1}} \Sigma\left(y_{1 i}-\widehat{y_{0 i}}\right),
$$

where $Y_{1 i}$ and $Y_{0 i}$ were, respectively, the income per capita for the participating and nonparticipating households, $N_{1}$ was the number of participating households, $y_{1 i}$ was the income per capita of NAC member $i$, and $y_{0 i}$ was the income per capita of NAC member $i$ if the household did not participate in NACs.

3.2.3. Endogenous Switching Regression Model. Even though PSM is able to effectively reduce the selection bias caused by observable variables such as education level, age, and land size, it has been found to be unreliable for unobservable variables such as farmer interest, cooperation consciousness, and innate ability endowment. ESR, therefore, can be used to address these PSM method defects. Combined with a counterfactual inference analysis and by, respectively, fitting the income determination equations of the NAC members and nonmembers, the ESR was able to reduce the effect of 
the unreasonable assumption that the two-group treatment impacts were homogeneous [23].

Similar to the PSM, the ESR built a household decisionmaking model using equation (1) to basically emphasize that the endogenous transformation model allowed the explanatory variables in $Z_{i j}$ to overlap with $X_{i j}$. To identify at least one variable (identification variable) in $Z_{i j}$ that was not included in $X_{i j}$, the variable needed to directly affect the household behavior and not directly affect their income level. This paper selected "minority" as the identification variable, the validity of which passed the $t$-test $\left(p_{\text {Miao }}=0.077, p_{\text {Tujia }} \leq 0.001\right)$ and the overidentification test (Hasen $J$ test) $\left(\chi^{2}=1.65, p=0.199\right)$. As this variable was exogenous, ethnic characteristics affected household cooperative participation but not income. The incomes were

$$
\begin{array}{ll}
Y_{1 i}=\beta_{1} X_{1 i}+u_{1 i}, & \text { if } C_{i}=1, \\
Y_{0 i}=\beta_{0} X_{0 i}+u_{0 i}, & \text { if } C_{i}=0,
\end{array}
$$

where $Y_{1 i}$ and $Y_{0 i}$ are, respectively, the income per capita for the participating and nonparticipating households, $X_{i}$ is the vector for the covariates included in $Z_{i}$, and $\beta_{1}$ and $\beta_{0}$ are the parameter vectors to be estimated.

Since it was not possible to observe the household incomes in both participation and nonparticipation cooperative situations and the conditional expectation of the random error term was not zero, biased results were obtained using the OLS estimations in equations (3) and (4). Therefore, $\quad \sigma_{v}^{2}=\operatorname{var}(v), \quad \sigma_{u_{1} v}=\operatorname{cov}\left(u_{1}, v\right), \quad$ and $\sigma_{u_{0} v}=\operatorname{cov}\left(u_{0}, v\right)$ were denoted and $\sigma_{v}^{2}$ was normalized to 1 , with the conditional expectations for $u_{1}$ and $u_{0}$ being determined as

$$
\begin{aligned}
& E\left(u_{1 i} \mid C_{i}=1\right)=E\left(u_{1 i} \mid \gamma_{1} Z_{i}+v_{i}>0\right)=\sigma_{u_{1} v} \frac{\phi\left(\gamma_{1} Z_{i}\right)}{\Phi\left(\gamma_{1} Z_{i}\right)}=\sigma_{u_{1}} \lambda_{1 i}, \\
& E\left(u_{0 i} \mid C_{i}=0\right)=E\left(u_{0 i} \mid \gamma_{0} Z_{i}+v_{i}>0\right)=\sigma_{u_{0} v} \frac{-\phi\left(\gamma_{0} Z_{i}\right)}{1-\Phi\left(\gamma_{0} Z_{i}\right)}=\sigma_{u_{0}} \lambda_{0 i},
\end{aligned}
$$

where $\phi\left(\gamma Z_{i}\right)$ and $\Phi\left(\gamma Z_{i}\right)$ denote the density function and cumulative probability density function for the standard normal distribution with $\gamma Z_{i}$ as the variables and $\left(\phi\left(\gamma_{1} Z_{i}\right) / \Phi\left(\gamma_{1} Z_{i}\right)\right)$ (denoted by $\left.\lambda_{1 i}\right)$ and $-\left(\phi\left(\gamma_{0} Z_{i}\right) / 1-\right.$ $\Phi\left(\gamma_{0} Z_{i}\right)$ ) (denoted by $\left.\lambda_{0 i}\right)$ represent the selection biases resulting from the unobservable variables, which were the Inverse Mills Ratios (IMR); that is, if $\sigma_{u_{1} v}$ and $\sigma_{u_{0} v}$ are significantly nonzero, it is necessary to correct the sample selection bias caused by the unobservable variables.

Therefore, the conditional household income expectations in the two participation and nonparticipation situations were

$$
\begin{aligned}
& E\left(Y_{1 i} \mid C_{i}=1\right)=\beta_{1} X_{1 i}+\sigma_{u_{1}} \lambda_{1 i}, \\
& E\left(Y_{0 i} \mid C_{i}=0\right)=\beta_{0} X_{0 i}+\sigma_{u_{0}} \lambda_{0 i},
\end{aligned}
$$

where equation (6) was the expected income effect of membership and equation (7) was the expected income effect of nonmembership. Therefore, the ESR model was able to calculate the observed and counterfactual incomes. As well as comparing the expected incomes of the participating households (equation (6)) and nonparticipating households (equation (7)), other expected incomes were also detected in the counterfactual hypothetical nonparticipating NAC households (equation (8)) and participating households (equation (9)).

$$
\begin{aligned}
& E\left(Y_{0 i} \mid C_{i}=1\right)=\beta_{0} X_{1 i}+\sigma_{u_{0}} \lambda_{1 i}, \\
& E\left(Y_{1 i} \mid C_{i}=0\right)=\beta_{1} X_{0 i}+\sigma_{u_{1}} \lambda_{0 i},
\end{aligned}
$$

where equation (8) was the expected income effect of a nonmembership, given that the household was an NAC member and equation (9) was the expected income effect of an NAC member given that the household was not an NAC member.

The average treatment effect (ATT) of members was calculated as

$\mathrm{ATT}=E\left(Y_{1 i} \mid C_{i}=1\right)-E\left(Y_{0 i} \mid C_{i}=1\right)=\left(\beta_{1}-\beta_{0}\right) X_{1 i}+\left(\sigma_{u_{1} v}-\sigma_{u_{0} v}\right) \lambda_{1 i}$,

and the average treatment effect of nonmembers (ATU) was $[67,68]$

$$
\mathrm{ATU}=E\left(Y_{1 i} \mid C_{i}=0\right)-E\left(Y_{0 i} \mid C_{i}=0\right)=\left(\beta_{1}-\beta_{0}\right) X_{0 i}+\left(\sigma_{u_{1} v}-\sigma_{u_{0} v}\right) \lambda_{0 i} .
$$

\section{Results and Discussion}

This section details the results for the NAC participation determinants and the PSM and ESR estimations.

4.1. NAC Participation Determinants. A logit regression model was used to select a set of covariates, 5 of which were significant at the $95 \%$ confidence interval (Table 2): Distance, Policy, Landsize, Nationality, and Education. The explanatory variables were found to be jointly statistically significant $\left(\right.$ LR $\chi^{2}(9)=112.69, p \leq 0.001$, Pseudo $R^{2}=0.1128, \log$ likelihoods $=-443.195$, and number of obs $=848$ ).

The estimation results obtained for the explanatory variables in the logit model have little substantive meaning and can therefore safely be omitted, and the significance of the explanatory variables does not need to be focused on, because the estimated coefficients of explanatory variables are likely to be biased anyway in practical applications. Instead, the marginal effects of the main variables should be rather focused on $[69,70]$, and the results showed heterogeneous policy perception and behavioral differences between the groups [71, 72].

As shown in Table 2, most minority NAC members were closer to the main road and had benefited from other poverty policies, which was consistent with Kirsten et al. [73]. It was also found that Tujia nationality households were more likely to be NAC members than Han and Miao nationality households. The number of migrant workers was found to be negatively related to NAC membership. As migrant workers mean that households have access to other income sources, 
TABle 2: Logit model results of variables affecting NAC membership.

\begin{tabular}{lcccc}
\hline Member & Coef. & $\mathrm{d} y / \mathrm{d} x$ & $z$ & $p>|z|$ \\
\hline Distance & -0.191 & -0.033 & -2.26 & $0.024^{* *}$ \\
Tujia & 1.582 & 0.275 & 7.88 & $\leq 0.001^{* * *}$ \\
Policy & 0.773 & 0.134 & 4.56 & $\leq 0.001^{* * *}$ \\
College & 0.806 & 0.134 & 3.14 & $0.002^{\text {*** }}$ \\
Landsize & 0.171 & 0.030 & 3.07 & $0.002^{\text {*** }}$ \\
Miao & 0.609 & 0.106 & 2.72 & $0.007^{\text {*** }}$ \\
Mwsize & -0.166 & -0.029 & -1.90 & $0.057^{*}$ \\
Primary & 0.424 & 0.074 & 2.11 & $0.035^{* *}$ \\
Sick & 0.253 & 0.044 & 1.47 & 0.142 \\
Constant & -3.327 & & -2.23 & $\leq 0.001$ \\
\hline
\end{tabular}

Note. Significance level: ${ }^{*} 10 \%,{ }^{* *} 5 \%$, and ${ }^{* * *} 1 \%$.

this may weaken household willingness to join an NAC. Household college and primary school education levels were found to have more positive and significant effects on the probability of cooperative membership than illiteracy, and land size was also found to have a significant and positive relationship with NAC membership probability, which was consistent with the findings by Bernard et al. [74] and Nugusse et al. [16].

4.2. PSM Estimation Results. The probability that each household participated in an NAC (the propensity score) was calculated in the logit model (Table 2). The tests for the PSM assumptions found that common support, overlap conditions, and the balancing property were fulfilled. There was a substantial overlap in the distribution of the estimated probability of membership (of both members and nonmembers) (Figure 1). Observations out of the support region were dropped from the sample, with the final sample size being 848 (229 members and 599 nonmembers) from which the ATT was estimated.

Standard biases across the matched object covariates were closer to 0 than the unmatched object covariates, which indicated that the standardized mean deviations for all covariates obviously reduced after the matching (Figure 2). The results from the four matching algorithms were consistent and all covariates were significantly reduced after the matching for all four (four-nearest neighbor, kernel, radius, and nearest neighbor within caliper) algorithms, the Pseudo $R^{2}$, the LR $\chi^{2}$, the mean standardized bias, and the median bias. The $p$ values from the likelihood ratio tests were equal to or close to 1 (0.928), which also indicated that there were insignificant covariant mean differences between the two groups after the matching (Table 3 ).

The PSM estimations showed that, on average, the NAC members had between 415.66 CNY and 629.84 CNY higher incomes than the nonmembers with $p \geq 0.1$, which was less than the 738 CNY result (Table 1). As the matching results were robust but not significant, this tended to imply that there were no income impacts associated with NAC membership. While PSM models are able to effectively estimate the average treatment effects in observational studies by conditioning the possible selection biases in the observable data, as they only control the observable selection
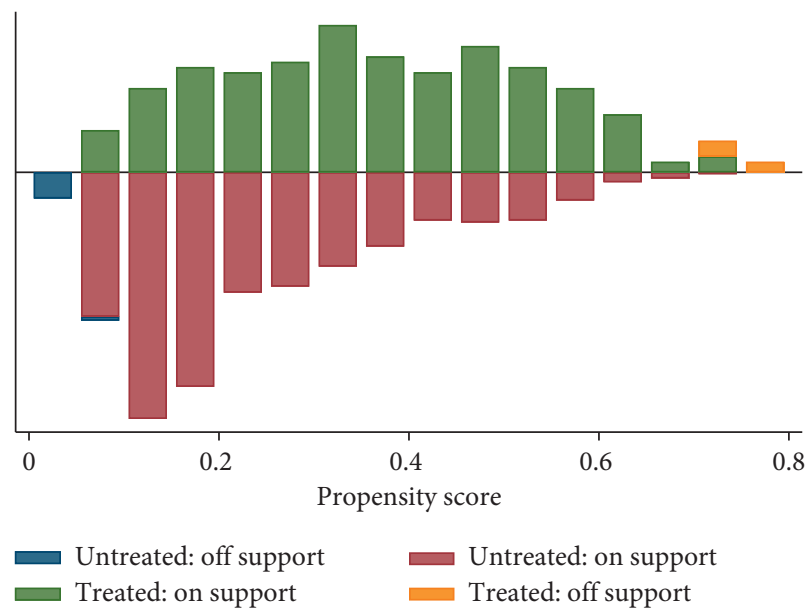

FIGURE 1: Common support of propensity scores.

biases, they may generate unreliable results if unobservable biases exist, that is, if the members and nonmembers are systematically different. Therefore, to account for the observable and unobservable biases, the ESR model was used to supplement the PSM findings (Table 4).

4.3. ESR Estimation Results. The first ESR model stage estimated equations (1), (3), and (4) using full information maximum likelihood, with the membership choice indicator $C_{i}$ being 1 if the household was participating in an NAC and 0 if not. $\rho_{1}$ is the correlation coefficient between the error term $v_{i}$ in equation (1) and the error term $u_{1 i}$ in equation (3), and $\rho_{0}$ is the correlation coefficient between the error term $v_{i}$ of equation (1) and the error term $u_{0 i}$ of equation (4). The results $\left(\rho_{1}=-0.238 ; \rho_{0}=-0.980\right)$ showed that $\rho_{0}$ was negative and significantly different from zero (Table 5), which suggested that the households not participating in the NACs had higher incomes than the random households in the sample and that the households participating in the NACs would have no better or no worse incomes than the random household, indicating that there was heterogeneity between the two groups.

The likelihood ratio tests for joint independence of the three income equation ( $\left.\operatorname{LR} \chi^{2}=122.19, p \leq 0.001\right)$ indicated that the error terms $u_{1 i}$ in equation (3) and $u_{0 i}$ in equation (4) were correlated and ignoring them could lead to biased results. Therefore, the use of the ESR models could reduce these biases.

The actual and counterfactual outcomes of being or not being an NAC member showed average treatment effects (Table 6). The findings in the diagonal cells were the predicted actual average incomes for both members and nonmembers, and the off-diagonal cells were the counterfactual outcomes for the members and nonmembers. The ATT indicated the treatment effect (NAC membership) on the treated group (i.e., NAC members) obtained by comparing (6) and (9), the ATU was the effect of the treatment (i.e., NAC membership) on the untreated group (i.e., nonmembers) obtained by comparing (8) and (7), H1 and $\mathrm{H} 2$ were the effects of the base heterogeneity for households 

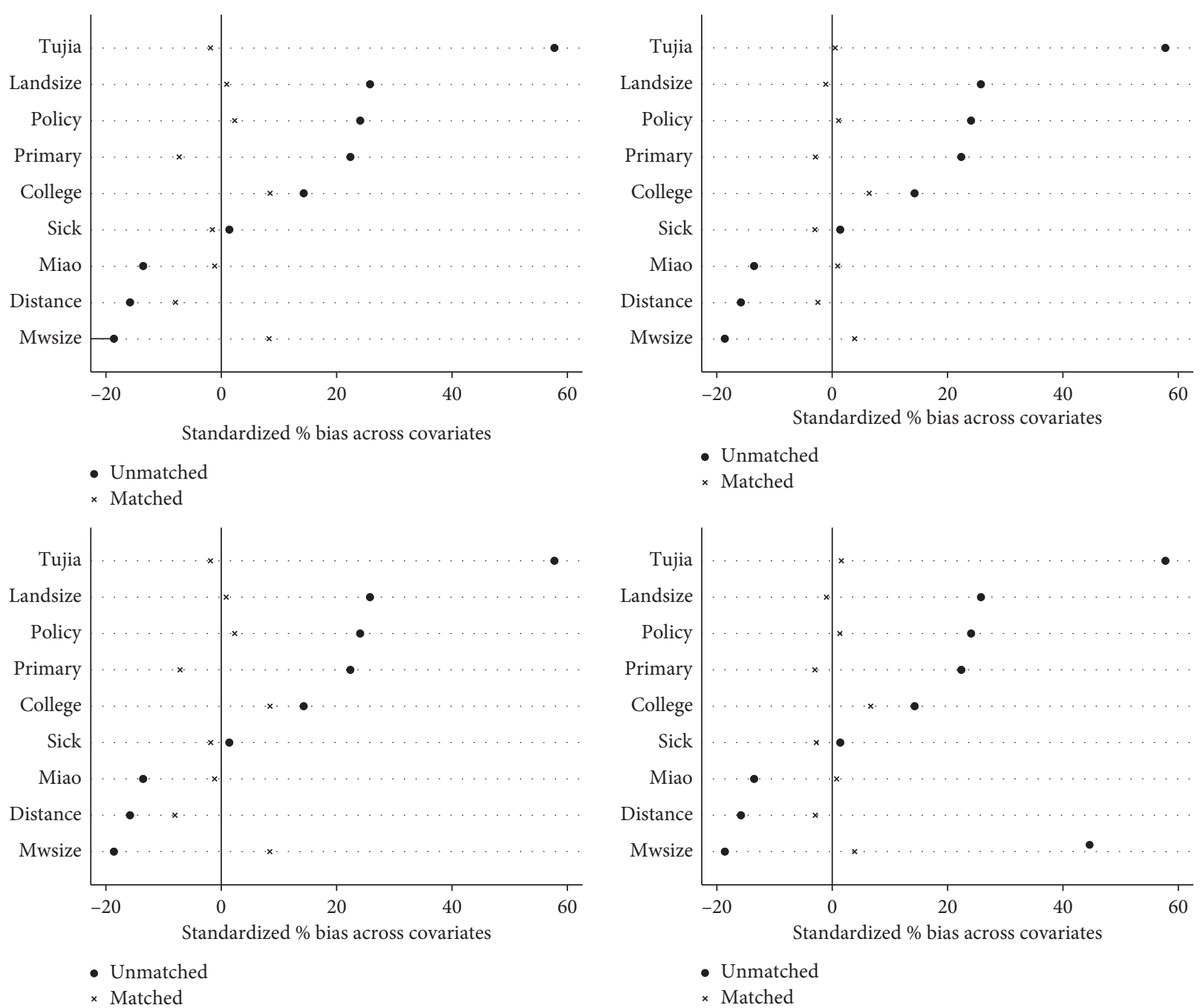

- Unmatched

$\times$ Matched

$\times$ Matched

FIgURE 2: Balance test of propensity scores.

TABLE 3: Matching quality test: balancing property.

\begin{tabular}{lccccc}
\hline \multirow{2}{*}{ Test for } & Before matching & \multicolumn{3}{c}{ After matching (algorithms) } \\
& & Four-nearest & Kernel & Radius & Nearest neighbor within caliper \\
\hline Pseudo $R^{2}$ & 0.113 & 0.004 & 0.001 & 0.004 & 0.001 \\
LR $\chi^{2}$ & 112.66 & 2.46 & 0.64 & 2.47 & 0.76 \\
$p$ value & $\leq 0.001$ & 0.928 & 1 & 0.928 & 1 \\
Mean standardized bias & 21.5 & 4.4 & 2.5 & 4.5 & 2.7 \\
Median bias & 18.6 & 2.3 & 2.5 & 2.3 & 2.7 \\
\hline
\end{tabular}

TABLE 4: PSM results: average income impact of NAC membership (in CNY).

\begin{tabular}{|c|c|c|c|c|c|c|c|}
\hline Outcome & Matching algorithms & Treated & Controls & ATT & Std. err. & $Z$ & $p$ value \\
\hline \multirow{4}{*}{ In 2018} & Four-nearest & 7741.788 & 7111.951 & 629.84 & 349.314 & 1.53 & 0.126 \\
\hline & Kernel & 7741.788 & 7309.930 & 431.86 & 326.996 & 1.32 & 0.188 \\
\hline & Radius & 7741.788 & 7114.520 & 627.27 & 349.175 & 1.53 & 0.125 \\
\hline & Nearest neighbor matching within caliper & 7741.788 & 7326.127 & 415.66 & 326.351 & 1.24 & 0.217 \\
\hline
\end{tabular}

Note. Significance level: ${ }^{*} 10 \%,{ }^{*} 5 \%$, and ${ }^{* * *} 1 \%$. ATT estimates of four-nearest neighbors, kernel (bandwidth $\left.=0.06\right)$, radius (caliper $\left.=0.06\right)$, and nearest neighbor matching within caliper (caliper $=0.06$ )-based matching are estimated using the "psmatch2" command in STATA. 
TABLE 5: Determinants of NAC membership and its impacts on income.

\begin{tabular}{|c|c|c|c|}
\hline \multirow{2}{*}{ Variables } & \multirow{2}{*}{ Selection } & \multicolumn{2}{|c|}{ In 2018} \\
\hline & & Members & Nonmembers \\
\hline Distance & $-0.016(0.699)$ & $25.476(0.926)$ & $-144.248(0.294)$ \\
\hline College & $0.301(0.024)^{* *}$ & $52.859(0.948)$ & $-190.676(0.713)$ \\
\hline Primary & $0.170(0.1)^{*}$ & $-175.235(0.787)$ & $-920.864(0.020)^{* *}$ \\
\hline Sick & $0.108(0.208)$ & $-402.134(0.466)$ & $-337.043(0.290)$ \\
\hline Mwsize & $-0.109(0.010)^{* * *}$ & $958.576(0.002)^{* * *}$ & $361.560(0.020)^{* * *}$ \\
\hline Landsize & $0.040(0.141)$ & $111.221(0.500)$ & $-75.053(0.381)$ \\
\hline Policy & $0.282(0.001)^{* * *}$ & $-95.873(0.872)$ & $-172.492(0.591)$ \\
\hline Miao & $0.065(0.388)$ & & \\
\hline Tujia & $0.268(0.001)^{* * *}$ & & \\
\hline $\operatorname{Ln} \sigma_{0}$ & & & $8.354(p<0.01)^{* * * *}$ \\
\hline $\operatorname{Ln} \sigma_{1}$ & & $8.283(p<0.01)^{* * * *}$ & \\
\hline$\rho_{0}$ & & & -0.980 \\
\hline$\rho_{1}$ & & -0.238 & \\
\hline LR $\chi^{2}$ & $122.19(p<0.01)^{* * * *}$ & & \\
\hline Observations & 848 & 848 & 848 \\
\hline
\end{tabular}

Note. Significance level: ${ }^{*} 10 \%,{ }^{* *} 5 \%$, and ${ }^{* * *} 1 \%$.

TABLE 6: ESR results: counterfactual conditions estimation and average treatment effects.

\begin{tabular}{lccc}
\hline & \multicolumn{2}{c}{ Decision stages } & Average treatment effects \\
\hline To be member & $(4) E\left(Y_{1 i} \mid C_{i}=1\right)=7764.4$ & Not to be member & ATT $=7220.5^{* * *}$ \\
Nonmembers & $(6) E\left(Y_{0 i} \mid C_{i}=1\right)=7852.3$ & $(5) E\left(Y_{1 i} \mid C_{i}=0\right)=543.94$ & ATU $=363.80^{* * *}=7488.5$ \\
Heterogeneity & $H 1=-87.9^{* * *}$ & $H 2=-6944.6^{* * *}$ & $H 3=6856.7^{* * *}$ \\
\hline
\end{tabular}

Note. Significance level: ${ }^{*} 10 \%,{ }^{* *} 5 \%$, and ${ }^{* * *} 1 \%$. Subsample size: members $=234$; nonmembers $=614$.

that participated or were not participating in the NACs, and H3 was the transitional heterogeneity.

Therefore, for actual total income, it was found that the NAC members earned $276 \mathrm{CNY}$ more than nonmembers $((4)-(5)=276)$, which was consistent with the results from the descriptive statistics $(738 \mathrm{CNY})$ and the results from the PSM estimations (416 CNY to $630 \mathrm{CNY}$ ); that is, NAC membership had a positive effect on household income.

The counterfactual outcomes inferred more details. Household NAC members would have earned about 7220 CNY or about 13 times less if they had not been members $((4)-(7)=7220)$, which was the average treatment effect on the treated (ATT). The income gap between members and nonmembers indicated the positive and significant impact of NAC membership. The differences adjusted for the potential sample heterogeneity showed that if member households had not been members, they would have earned $6945 \mathrm{CNY}$ less than the nonmember households $((7)-(5)=-6945)$, which indicated that the NAC members would have had worse income generation capabilities than the nonmembers if they had not been members of the NACs. This finding indicates that the current NAC probably comes from worseoff groups, which was consistent with the reality investigated in the study area as most of the participating households had poor income generating abilities. Therefore, it could be surmised that the access to the funds, technology, and markets provided by the NACs greatly increased their income.

Nonmember households would have earned about 363 CNY (i.e., about 5 percent) more if they had been NAC members $((6)-(5)=363)$, that is, the average treatment effect on the untreated (ATU). This increase in nonmember income was far less than for the members, indicating that there was a positive but limited impact of the NACs even for nonparticipating households. Similarly, if the current nonmembers had been members, they would have earned slightly higher incomes (about $88 \mathrm{CNY}, 1 \%$ percent more) than the actual members $((4)-(6)=-88)$. The nonparticipating households, who were more likely to be better-off groups, benefited from the NAC through slightly higher incomes. As discussed, without the NAC services, the nonmembers earned significantly more than the members; however, the NACs have narrowed the capability differences, with the worse-off groups gaining the most.

The transitional heterogeneity (i.e., H3) indicated that the members would have gained $6857 \mathrm{CNY}$ more than the actual nonmembers; that is, the average effect of membership was significantly larger for the actual members relative to actual nonmembers if they had been members, which implies that NAC membership was positively associated with both member and nonmember household income. However, there are capability differences between poor groups, with the NACs more effectively increasing the incomes of the worse-off groups and being less attractive to better-off groups. This was in line with the original intentions of the NACs to alleviate poverty but was inconsistent with the conclusions by Mojo et al. [9], which found that those that joined cooperatives were the better-off groups and that the members had better earning capabilities than the nonmembers. These research result differences could be 
because of the special social environments in ethnic areas. The households that tend to participate in the NACs have been found to have closer geographical, group, and psychological distances to the policy. The research investigation revealed that the ethnic areas communicate less with other regions and have more geographical, traffic, historical, and cultural constraints; that is, as the worse-off groups in these ethnic areas barely communicate with the outside world, they are more likely to benefit from and rely on national policies, whereas the better-off groups take the opportunity to maintain contact with the outside world and may have more ways to generate income.

While the absolute total income differences between the NAC members and nonmembers were relatively small (276 CNY), the income differences were huge (6857 CNY) under counterfactual interference, which means that the NACs could also lead to group inequalities. As the actual total incomes of the better-off households were found to be lower than the worse-off groups, even if they joined the cooperatives, their incomes may not significantly improve.

Generally, the PSM and ESR model results indicated that there was a positive association between NAC membership and household income. However, compared with the ESR model estimations, the PSM model results were lower, which could have been because of the unobservable heterogeneity not accounted for in the PSM. Similar inconsistencies between PSM and ESR results have been observed in other studies (Shiferaw et al. [75] and Mojo et al. [9]), which also found insignificant PSM estimates, and significant ESR estimates. The endogenous transformation model is a more rigorous method for policy evaluation or program evaluation.

\section{Conclusion}

This paper examined NAC in Southwest China to assess the balance and policy implementation deviations in ethnic minority areas. To exclude endogeneity (selection bias) and heterogeneity, PSM and ESR were employed to evaluate the income effects, heterogeneous policy perceptions, and the effect of cooperative membership, from which the following conclusions were made.

(1) Heterogeneous policy perceptions and behavioral differences between the groups influenced the household willingness to participate in NACs in ethnic areas.

(2) Being a member of the NACs had a positive impact on household income per capita, which provided evidence for the effectiveness of agricultural cooperatives in alleviating poverty.

(3) Capability differences in income generation were found between members and nonmembers. Even though the member and nonmember incomes were similar, it was found that members benefited more by being members than the nonmembers and that NACs more effectively increased the incomes of worse-off groups.
Therefore, the following recommendations are given:

(1) Given the influences of households' perception and behavior differences on the NAC membership decisions, policymakers should pay greater attention to develop more appropriate measures to reduce the imbalances caused by the policy perception and behavioral and earning capability differences between groups. For example, government and extension services could provide household training programs to enhance households' understanding of the important roles of NACs and increase the trust.

(2) The findings of a positive relationship between cooperative membership and family income of poor households suggest that policymakers should continue with policy incentives to encourage poor smallholders to join NACs and formulate measures to promote the development of the NACs to promote poverty alleviation.

(3) The findings of the group differences in the incomeincreasing effect of cooperatives provide crucial policy insights for policymakers. Our findings that if the existing cooperative members do not join the cooperative, the income will drop precipitously, and if the existing nonmembers join the cooperative, the income will not change much show that the earning ability of existing members is weak, and their earning ability has been greatly improved with the help of cooperatives. On the other hand, the income-increasing effect of cooperatives on the groups with strong earning ability (even if they do not join the cooperatives, their income is not low) is weak. It suggests that local governments should concern the demands of the better-off poor groups (with strong earning ability) and provide more effective services for heterogeneous groups.

This paper provided a research perspective and framework for effect evaluations. As the geographical scope of this study was limited to Southwest China, future studies should assess the effects of agricultural cooperatives in other developing countries using the methodology outlined in this paper. To further detect group heterogeneity, quantile regression could also be used, and to detect the random effects of time, a multilevel model could be used.

\section{Data Availability}

The data that support the finding of this study are available from the State Council Leading Group Office of Poverty Alleviation and Development of China. Restrictions apply to the availability of these data, which were used under license for this study. Data are available at http://cpadis.cpad.gov.cn: 9300/cpad_query/login with the permission of the State Council Leading Group Office of Poverty Alleviation and Development of China. The data that support the finding of this study are also available upon request from the corresponding author. The data are not publicly available due to privacy or ethical restrictions. 


\section{Conflicts of Interest}

The authors declare that they have no conflicts of interest.

\section{Acknowledgments}

This paper was supported by the Chinese National Funding of Social Science (Grant no. 18AGL022).

\section{References}

[1] A. Mani, S. Mullainathan, E. Shafir, and J. Zhao, "Poverty impedes cognitive function," Science, vol. 341, no. 6149, pp. 976-980, 2013.

[2] B. Manish, "Correction," Nature, vol. 489, no. 7416, p. 367, 2012.

[3] C. Liao and D. Fei, "Poverty reduction through photovoltaicbased development intervention in China: potentials and constraints," World Development, vol. 122, pp. 1-10, 2019.

[4] P. Seuneke, T. Lans, and J. S. C. Wiskerke, "Moving beyond entrepreneurial skills: key factors driving entrepreneurial learning in multifunctional agriculture," Journal of Rural Studies, vol. 32, pp. 208-219, 2013.

[5] C. Chagwiza, R. Muradian, and R. Ruben, "Cooperative membership and dairy performance among smallholders in Ethiopia," Food Policy, vol. 59, pp. 165-173, 2016.

[6] J. Hao, J. Bijman, C. Gardebroek, N. Heerink, W. Heijman, and X. Huo, "Cooperative membership and farmers' choice of marketing channels-evidence from apple farmers in Shaanxi and Shandong Provinces, China," Food Policy, vol. 74, pp. 53-64, 2018.

[7] W. Ma, A. Abdulai, and R. Goetz, "Agricultural cooperatives and investment in organic soil amendments and chemical fertilizer in China," American Journal of Agricultural Economics, vol. 74, pp. 53-64, 2018.

[8] J. Michalek, P. Ciaian, and J. Pokrivcak, "The impact of producer organizations on farm performance: the case study of large farms from Slovakia々," Food Policy, vol. 75, pp. 80-92, 2018.

[9] D. Mojo, C. Fischer, and T. Degefa, "The determinants and economic impacts of membership in coffee farmer cooperatives: recent evidence from rural Ethiopia," Journal of Rural Studies, vol. 50, pp. 84-94, 2017.

[10] T. Wossen, T. Abdoulaye, A. Alene et al., "Impacts of extension access and cooperative membership on technology adoption and household welfare," Journal of Rural Studies, vol. 54, pp. 223-233, 2017.

[11] H. Hoken and Q. Su, "Measuring the effect of agricultural cooperatives on household income: case study of a riceproducing cooperative in China," Agribusiness, vol. 34, no. 4, pp. 831-846, 2018.

[12] J. Ito, Z. Bao, and Q. Su, "Distributional effects of agricultural cooperatives in China: exclusion of smallholders and potential gains on participation," Food Policy, vol. 37, no. 6, pp. 700-709, 2012.

[13] W. Ma and A. Abdulai, "The economic impacts of agricultural cooperatives on smallholder farmers in rural China," Agribusiness, vol. 33, p. 5378C551, 2017.

[14] L. Meng, "Evaluating China's poverty alleviation program: a regression discontinuity approach," Journal of Public Economics, vol. 101, pp. 1-11, 2013.

[15] W. Ma, A. Renwick, P. Yuan, and N. Ratna, "Agricultural cooperative membership and technical efficiency of apple farmers in China: an analysis accounting for selectivity bias," Food Policy, vol. 81, p. 1228C132, 2018.

[16] W. Zeweld Nugusse, G. Van Huylenbroeck, and J. Buysse, "Determinants of rural people to join cooperatives in northern Ethiopia," International Journal of Social Economics, vol. 40, no. 12, pp. 1094-1107, 2013.

[17] G. T. Abate, G. N. Francesconi, and K. Getnet, "Impact of agricultural cooperatives on smallholders' technical efficiency: evidence from Ethiopia," Annals of Public \& Cooperative Economics, vol. 85, pp. 257-286, 2013.

[18] K. M. Gedara, C. Wilson, S. Pascoe, and T. Robinson, "Factors affecting technical efficiency of rice farmers in village reservoir irrigation systems of Sri Lanka," Journal of Agricultural Economics, vol. 63, no. 3, pp. 627-638, 2012.

[19] G. Hailu, A. Weersink, and B. J. Minten, "Rural organizations, agricultural technologies and production efficiency of teff in Ethiopia," in Proceedings of International Association of Agricultural Economists, Milan, Italy, August 2015.

[20] D. Abebaw and M. G. Haile, "The impact of cooperatives on agricultural technology adoption: empirical evidence from Ethiopia," Food Policy, vol. 38, pp. 82-91, 2013.

[21] B. Bayan, "Impacts of dairy cooperatives in smallholder dairy production systems: a case study in Assam," Agricultural Economics Research Review, vol. 31, no. 1, pp. 87-94, 2018.

[22] E. Verhofstadt and M. Maertens, "Smallholder cooperatives and agricultural performance in Rwanda: do organizational differences matter?" Agricultural Economics, vol. 45, no. S1, pp. 39-52, 2014.

[23] W. Ma and A. Abdulai, "Does cooperative membership improve household welfare? evidence from apple farmers in China," Food Policy, vol. 58, pp. 94-102, 2016.

[24] E. Fischer and M. Qaim, "Linking smallholders to markets: determinants and impacts of farmer collective action in Kenya," World Development, vol. 40, no. 6, pp. 1255-1268, 2012.

[25] D. Mojo, C. Fischer, and T. Degefa, "Collective action and aspirations: the impact of cooperatives on Ethiopian coffee farmers' aspirations," Annals of Public And Cooperative Economics, vol. 87, no. 2, pp. 217-238, 2016.

[26] S. Dhahri and A. Omri, "Entrepreneurship contribution to the three pillars of sustainable development: what does the evidence really say?" World Development, vol. 106, pp. 64-77, 2018.

[27] D. Mojo, C. Fischer, and T. Degefa, "Social and environmental impacts of agricultural cooperatives: evidence from Ethiopia," International Journal of Sustainable Development \& World Ecology, vol. 22, pp. 388-400, 2015.

[28] P. S. Ward, "Transient poverty, poverty dynamics, and vulnerability to poverty: an empirical analysis using a balanced panel from rural China," World Development, vol. 78, pp. 541-553, 2016.

[29] M. Mabuza, G. Ortmann, and E. Wale, "Collective action in small-scale mushroom production in Swaziland: does organisational form matter?" Development in Practice, vol. 25, no. 7, pp. 1025-1042, 2015.

[30] A. R. Quisumbing and L. Pandolfelli, "Promising approaches to address the needs of poor female farmers: resources, constraints, and interventions," World Development, vol. 38, no. 4, pp. 581-592, 2010.

[31] J. Ochieng, B. Knerr, G. Owuor, and E. Ouma, "Strengthening collective action to improve marketing performance: evidence from farmer groups in central africa," Journal of Agricultural Education and Extension, vol. 2, pp. 1-21, 2018. 
[32] L. M. Williams, "Perceptions versus objective measures of environmental quality in combined revealed and stated preference models of environmental valuation," Journal of Environmental Economics \& Management, vol. 32, pp. 65-84, 1997.

[33] J. Lingel, "Information tactics of immigrants in urban environments," Information Research, vol. 16, pp. 165-175, 2011.

[34] C. Fang, J. Giles, P. O'Keefe, and D. Wang, "The elderly and old age support in rural China: challenges and prospects," Population and Development Review, vol. 39, pp. 168-169, 2012.

[35] P. Haki, B. Erwin, A. Adewale, and D. Aliou, "Decentralised innovation systems and poverty reduction: experimental evidence from central africa," European Review of Agricultural Economics, vol. 1, pp. 99-127, 2015.

[36] R. Kheyroddin, R. Piroozi, and A. Soleimani, "Metastatic spread of luxury second homes in rural areas: a new type of spatial development in the tehran metropolitan region: a study of damavand county, Iran," Journal of Architectural and Planning Research, vol. 34, pp. 71-88, 2017.

[37] H. E. Miguel, A. L. Narciso, and M. M. Gustavo, "Farmers' satisfaction and intention to continue membership in agricultural marketing co-operatives: neoclassical versus transaction cost considerations," European Review of Agricultural Economics, vol. 2, pp. 239-260, 2013.

[38] S. L. Stattman and A. P. J. Mol, "Social sustainability of brazilian biodiesel: the role of agricultural cooperatives," Geoforum, vol. 54, pp. 282-294, 2014.

[39] K. Getnet and T. Anullo, "Agricultural cooperatives and rural livelihoods: evidence from Ethiopia," Annals of Public and Cooperative Economics, vol. 83, no. 2, pp. 181-198, 2012.

[40] A. B. Milford and A. Birgitte, "Co-operative or coyote? Producers' choice between intermediary purchasers and Fairtrade and organic co-operatives in Chiapas," Agriculture and Human Values, vol. 31, no. 4, pp. 577-591, 2014.

[41] T. S. Jayne, D. Mather, and E. Mghenyi, "Principal challenges confronting smallholder agriculture in sub-saharan africa," World Development, vol. 38, no. 10, pp. 1384-1398, 2010.

[42] W. Ma and A. Abdulai, "IPM adoption, cooperative membership and farm economic performance," China Agricultural Economic Review, vol. 11, no. 2, pp. 218-236, 2019.

[43] J. Manda, M. G. Khonje, A. D. Alene, A. H. Tufa, and V. Manyong, "Does cooperative membership increase and accelerate agricultural technology adoption? empirical evidence from Zambia," Technological Forecasting and Social Change, vol. 158, pp. 120-160, 2020.

[44] G. N. Francesconi and R. Ruben, "The hidden impact of cooperative membership on quality management: a case study from the dairy belt of Addis Ababa," Journal of Entrepreneurial \& Organizational Diversity, vol. 1, pp. 85-103, 2012.

[45] M. Liu, S. Min, W. Ma, and T. Liu, "The adoption and impact of e-commerce in rural China: application of an endogenous switching regression model," Journal of Rural Studies, vol. 83, pp. 106-116, 2021.

[46] Y. Liu, W. Ma, A. Renwick, and X. Fu, "The role of agricultural cooperatives in serving as a marketing channel: evidence from low-income regions of Sichuan province in China," International Food and Agribusiness Management Review, vol. 22, no. 2, pp. 265-282, 2019.

[47] G. Mujawamariya, M. D'Haese, and S. Speelman, "Exploring double side-selling in cooperatives, case study of four coffee cooperatives in Rwanda," Food Policy, vol. 39, pp. 72-83, 2013.

[48] L. Priscilla and A. K. Chauhan, "Economic impact of cooperative membership on dairy farmers in Manipur: a propensity score matching approach," Agricultural Economics Research Review, vol. 32, no. 1, p. 117, 2019.

[49] S. Traore, "Farmer organizations and maize productivity in rural Burkina Faso: the effects of the diversion strategy on cotton input loans," Review of Development Economics, vol. 4, p. 126, 2020.

[50] W. Ma, H. Zheng, Y. Zhu, and J. Qi, "Effects of cooperative membership on financial performance of banana farmers in China: a heterogeneous analysis," Annals of Public and Cooperative Economics, pp. 1-23, 2021, inpress.

[51] K. O. Olagunju, A. I. Ogunniyi, Z. Oyetunde-Usman, A. O. Omotayo, and B. A. Awotide, "Does agricultural cooperative membership impact technical efficiency of maize production in Nigeria: an analysis correcting for biases from observed and unobserved attributes," PLoS One, vol. 16, no. 1, p. e0245426, 2021.

[52] R. Qu, Y. Wu, J. Chen, G. D. Jones, and L. J. Frewer, "Effects of agricultural cooperative society on farmers' technical efficiency: evidence from stochastic frontier analysis," Sustainability, vol. 12, pp. 81-94, 2020.

[53] R. Cai, W. Ma, and Y. Su, "Effects of member size and selective incentives of agricultural cooperatives on product quality," British Food Journal, vol. 118, no. 4, pp. 858-870, 2016.

[54] C. Ji, S. Jin, H. Wang, and C. Ye, "Estimating effects of cooperative membership on farmers' safe production behaviors: evidence from pig sector in China," Food Policy, vol. 83, pp. 231-245, 2019.

[55] A. Adong, "Impact of households' membership of farmer groups on the adoption of agricultural technologies in Uganda: evidence from the Uganda Census of Agriculture 2008/09," Agrekon, vol. 53, no. 2, pp. 108-136, 2014.

[56] G. F. Ortmann and R. P. King, "Agricultural cooperatives i: history, theory and problems," Agrekon, vol. 46, no. 1, pp. 18-46, 2007.

[57] S. Alkire and A. Sumner, "Multidimensional poverty and the post-2015 mdgs," Development, vol. 56, no. 1, pp. 46-51, 2013.

[58] W. Bossert, S. R. Chakravarty, and C. D’Ambrosio, "Multidimensional poverty and material deprivation with discrete data," Review of Income and Wealth, vol. 59, no. 1, pp. 29-43, 2013.

[59] Y. Liu, J. Liu, and Y. Zhou, "Spatio-temporal patterns of rural poverty in China and targeted poverty alleviation strategies," Journal of Rural Studies, vol. 52, pp. 66-75, 2017.

[60] F. W. Agbola, A. Acupan, and A. Mahmood, "Does microfinance reduce poverty? new evidence from northeastern mindanao, the Philippines," Journal of Rural Studies, vol. 50, pp. 159-171, 2017.

[61] B. Bosco, "One size does not fit all: quantile regression estimates of cross-country risk of poverty in europe," Economic Analysis and Policy, vol. 62, pp. 280-299, 2019.

[62] Y. Ge, Y. Yuan, S. Hu, Z. Ren, X. Wang, and Y. Wu, "Spacetime variability analysis of poverty alleviation performance in China's poverty-stricken areas," Spatial Statistics, vol. 21, pp. 181-195, 2017.

[63] Y. Wu, Y. Ke, T. Zhang, F. Liu, and J. Wang, "Performance efficiency assessment of photovoltaic poverty alleviation projects in China: a three-phase data envelopment analysis model," Energy, vol. 159, pp. 599-610, 2018.

[64] G. J. C. Bacarreza and M. M. Hanauer, "Estimating the impacts of Bolivia's protected areas on poverty," Word Development, vol. 41, pp. 265-285, 2017.

[65] P. J. Ferraro, J. N. Sanchirico, and M. D. Smith, "Causal inference in coupled human and natural systems," Proceedings 
of the National Academy of Sciences, vol. 116, no. 12, pp. 5311-5318, 2018.

[66] M. Caliendo and S. Kopeinig, "Some practical guidance for the implementation of propensity score matching," Journal of Economic Surveys, vol. 22, no. 1, pp. 31-72, 2008.

[67] A. Amare and B. Simane, "Does adaptation to climate change and variability provide household food security? evidence from muger sub-basin of the upper blue-Nile, Ethiopia," Ecological Processes, vol. 7, no. 1, p. 13, 2018.

[68] J. J. Heckman, "Microdata, heterogeneity and the evaluation of public policy," Journal of Political Economy, vol. 109, pp. 673-748, 2000.

[69] C. Cinelli and C. Hazlett, "Making sense of sensitivity: extending omitted variable bias," Journal of the Royal Statistical Society: Series B (Statistical Methodology), vol. 82, no. 1, pp. 39-67, 2020.

[70] L. Keele, R. T. Stevenson, and F. Elwert, "The causal interpretation of estimated associations in regression models," Political Science Research and Methods, vol. 8, no. 1, pp. 1-13, 2020.

[71] G. C. Matchaya and V. Perotin, "The impact of cooperative patronage: the case of national small holder farmers' association (NASFAM) of Malawi in Kasungu district," Agrekon, vol. 52, no. 2, pp. 75-103, 2013.

[72] K. T. Sebhatu, T. W. Gezahegn, T. Berhanu, M. Maertens, S. V. Passel, and M. D'Haese, "Conflict, fraud, and distrust in ethiopian agricultural cooperatives," Journal of Co-operative Organization and Management, vol. 8, pp. 1-14, 2020.

[73] J. Kirsten, W. Ben, and O. Phil, "Theseson peasantry revisited," Antipode, vol. 37, pp. 944-955, 2005.

[74] T. Bernard, M.-H. Collion, A. de Janvry, P. Rondot, and E. Sadoulet, "Do village organizations make a difference in african rural development? a study for Senegal and Burkina Faso," World Development, vol. 36, no. 11, pp. 2188-2204, 2008.

[75] B. Shiferaw, M. Kassie, M. Jaleta, and C. Yirga, "Adoption of improved wheat varieties and impacts on household food security in Ethiopia," Food Policy, vol. 44, pp. 272-284, 2014. 